\title{
Effects of the intensity and frequency of organic enrichment on two estuarine nematode communities
}

\author{
Michaela Schratzberger ${ }^{1,2, *}$, Richard M. Warwick ${ }^{1}$ \\ ${ }^{1}$ Plymouth Marine Laboratory, Prospect Place, West Hoe, Plymouth PL1 3DH, United Kingdom \\ ${ }^{2}$ Institut für Hydrobiologie und Fischereiwissenschaft, Zeiseweg 9, D-22765 Hamburg, Germany
}

\begin{abstract}
The environmental management of anthropogenic inputs of organic materials to the sea requires a knowledge of the effects of different intensities and frequencies of input in relation to the nature of the receiving assemblages of organisms. A microcosm experiment was carried out to study whether the response of nematode communities to 3 different quantities of organic matter (high/medium/low) given once at the beginning of the experiment differs from the response to the same quantities given in several smaller doses during the experimental period. Communities from an organic-poor sandy estuary and an organic-rich muddy estuary were compared. Marked changes in community structure were revealed, depending on the total quantity of organic matter, the number of doses being administered during the experimental period and the environment where the communities had developed naturally. In the sand microcosms most univariate measures, including diversity and species richness, decreased significantly with increasing level of organic enrichment, whereas evenness increased in some cases. Nematode assemblages from the muddy estuary remained unaffected in the low additions; medium and high additions of organic matter resulted in significant decreases of most univariate measures. Results from multivariate analyses of the species abundance data revealed significant differences between undisturbed controls and organically enriched treatments for both nematode assemblages. In the sand microcosms, characteristic nematode communities developed which reflected different levels of organic enrichment. Changes in community structure were not as extreme in the mud microcosms. An increasing amount of organic matter led to a decrease of diversity caused by declining abundances of dominant nematode species. Both univariate and multivariate analyses of the data showed that the same amount of organic matter administered in many small doses had a milder effect on community structure than when administered in fewer but larger doses.
\end{abstract}

KEY WORDS: Organic enrichment - Nematodes - Estuaries - Microcosm experiment - Community structure Environmental management

\section{INTRODUCTION}

Natural sources of organic matter in inshore waters are the breakdown of macroalgae and terrestrial primary production, phytoplankton, and zooplankton faecal pellets and exuvia. Deposition of this natural organic material in most inshore areas is estimated to be below $100 \mathrm{~g} \mathrm{C} \mathrm{m}^{-2} \mathrm{yr}^{-1}$ (Gee \& Warwick 1985). Man's activity (e.g. sewage disposal) has resulted in an artificially high input of nutrients and organic matter

•E-mail: msch@pml.ac.uk into many coastal and offshore areas, raising the organic content of the sediment compared to natural levels. An excess of organic inputs into the marine environment can create an unbalanced ecosystem with high environmental stress (Austen \& Warwick 1995). The management of such impacts requires many decisions to be made on the basis of the best available scientific information. Effects can be minimised, for example, by selection of the most appropriate disposal area (in relation to the sensitivity of the receiving assemblage of organisms) and by controlling the frequency and intensity of the input of organic waste (large infrequent inputs vs frequent small ones). 
Laboratory experiments with field-collected benthic fauna have proved to be a suitable approach to study the effects of organic enrichment on marine communities (Coull \& Chandler 1992). Meiofaunal assemblages are ideal for experiments because of their short lifecycles and therefore their potential for rapid responses to environmental change (Warwick et al. 1988, Warwick 1993). A number of field and laboratory experiments have dealt with the effect of different loadings of organic material added once at the beginning of the experiment, community structures in undisturbed controls and treatments then being compared at the end of the experimental period (Gee \& Warwick 1985, Sandulli \& De Nicola Giudici 1989, Sundback et al. 1990 , Webb 1996).

There is still a lack of studies assessing the effects of different levels and frequencies of organic dosage in relation to the nature of the environment. Here, we present the results of a microcosm experiment designed to evaluate the effect of different quantities of organic matter on nematode community structure. The objective was to study whether the response of nematodes to a certain quantity of organic matter given once at the beginning of the experiment differs from the response to the same quantity given in several smaller doses during the experimental period. The investigation focused on the comparison of nematode assemblages derived from 2 estuaries in SW England: the seaward end of the Exe estuary, where the sediments comprise organic-poor sand, and the Lynher estuary comprising organic-rich muddy sediments. We intuitively expected that the nematode assemblage from the sandy Exe estuary would be more affected by organic enrichment than the mud community from the Lynher estuary, but we had no a priori expectation in relation to the frequency of dosing or the precise nature of the effects.

\section{MATERIAL AND METHODS}

Collecting sites. Intertidal estuarine sediments with their natural meiofaunal communities were collected from 2 estuaries in southwest England at low tide. Sand was collected from Cockle Sands near the mouth. of the Exe estuary at mean low water level. $10 \mathrm{~cm}$ diameter cores were used to a depth of $5 \mathrm{~cm}$ to transfer sand into a bucket. The sediment had a median particle diameter of $270 \mu \mathrm{m}$ (corresponding to the Wentworth grade 'Medium Sand'), and with $0 \%$ silt/clay $(<63 \mu \mathrm{m})$. The organic content of the sediment in this area is about $2 \%$ (A. Lindley pers. comm.). Mud from mid-tide level near Antony (Lynher estuary) was scraped into a bucket from the top $0.5 \mathrm{~cm}$ using a spade. The sediment had a median particle diameter of
$15 \mu \mathrm{m}$ (Wentworth grade 'Silt') with $98 \%$ silt clay. The organic content of the sediment is 12 to $13 \%$ (Warwick \& Price 1975). On return to the laboratory, sediment from each site was homogenised by gentle hand-stirring with a large spatula and subsamples for the microcosms were taken (Schratzberger \& Warwick 1998).

Experimental set-up. Microcosms consisted of $567 \mathrm{ml}$ glass bottles (max. diameter $=7 \mathrm{~cm}$, height $=$ $18 \mathrm{~cm}$ ). Sand microcosms were filled with $300 \mathrm{~g}$ of homogenised Exe sand and topped up with filtered seawater of $32 \mathrm{~S}$. Mud microcosms were filled with $150 \mathrm{~g}$ of homogenised Lynher mud and topped up with filtered seawater of $28 \mathrm{~S}$. The microcosms were run as closed systems with aeration (Fig. 1). The same kind of experimental set-up was tested successfully by Austen et al. (1994) and Schratzberger \& Warwick (1998). Organic enrichment was effected by the addition of powdered Ascophyllum nodosum (L.) Le Jol. in total quantities equivalent to 400,200 and $100 \mathrm{~g} \mathrm{C} \mathrm{m}^{-2}$ to the microcosms in 1 to 16 doses after $1 \mathrm{wk}$ of acclimatisation. High amounts of organic matter were chosen to optimise potential enrichment effects. The powdered algae was sprinkled into the microcosms. The $A$. nodosum used for the experiment contained 35\% carbon and $1 \%$ nitrogen. For both sand and mud microcosms there were 4 replicate control microcosms which remained unmanipulated and 15 treatments with 4 replicates each (Fig, 2). All experiments were terminated after $62 \mathrm{~d}$ and the sediments fixed in $4 \%$ formalin.

Sample processing. After decanting the sand samples 5 times onto a $63 \mu \mathrm{m}$ sieve, or after initially washing the mud samples onto a $63 \mu \mathrm{m}$ sieve, meiofauna

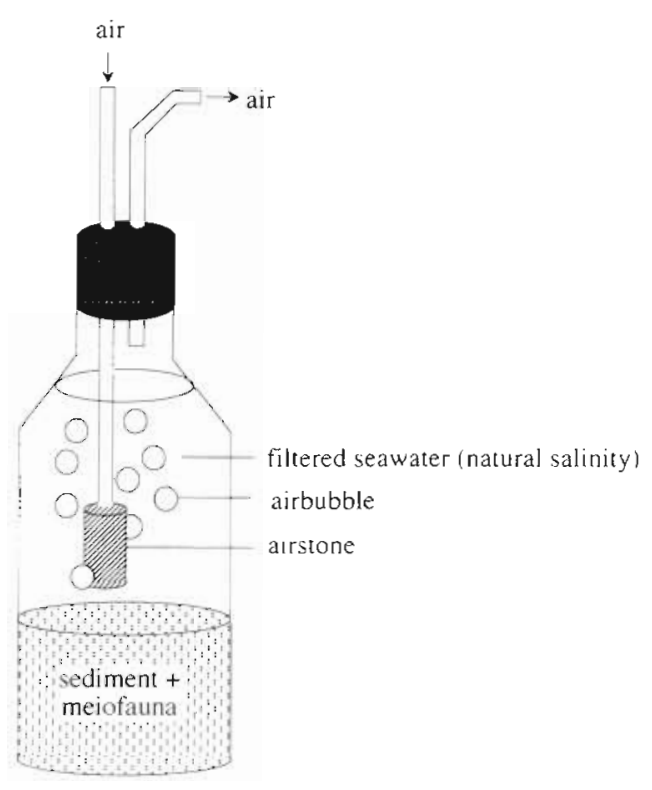

Fig. 1. Schematic diagram of a microcosm 


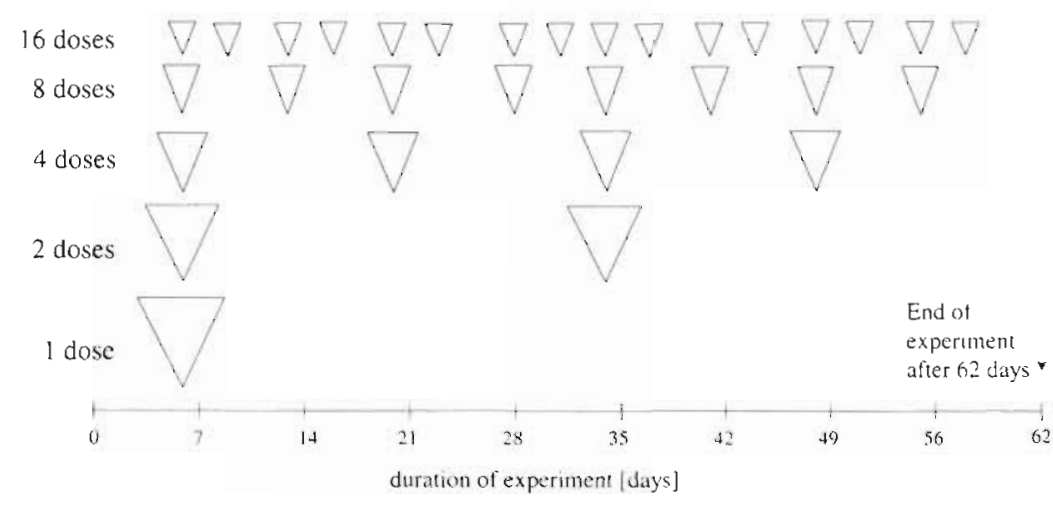

Fig. 2. Experimental treatments of organic enrichment. Three different total amounts of Ascophyllum nodosum (low addition $=100 \mathrm{~g} \mathrm{C} \mathrm{m}^{-2}$; medium addition $=200 \mathrm{~g} \mathrm{C} \mathrm{m}^{-2}$; high addition $=400 \mathrm{~g} \mathrm{C} \mathrm{m}^{-2}$ ) were given in 5 different numbers of doses

was extracted with Ludox following the procedure described in McIntyre \& Warwick (1984). The extraction was repeated 3 times for each sediment type. Due to the high nematode abundance in both sand and mud, subsamples were taken with a ladle after the meiofauna sample had been made up to a standard volume. Subsamples containing at least 200 specimens for identification were evaporated slowly into anhydrous glycerol and mounted evenly spread on slides for identification and counting under a microscope (Somerfield \& Warwick 1996). Nematodes were identified to genus or species using the pictorial keys of Platt \& Warwick $(1983,1988)$ and Warwick et al. (1997).

Data processing. Total nematode abundance, number of species, diversity (Shannon-Weaver index $H^{\prime}$ ), species richness (Margalef's $d$ ) and evenness (Pielou's J) were calculated for each microcosm. The KruskalWallis 1 -way analysis by ranks was applied, in which the values of a variable are transformed to ranks, ignoring group membership. These ranks were used to test the null hypothesis $\left(\mathrm{H}_{0}\right)$ that there was no significant shift in the centre of the groups, i.e. that the centres did not differ (Elliott 1971). After $\mathrm{H}_{0}$ was rejected, multiple comparisons tests were performed, following the procedure described by Conover (1980). The multiple comparisons tests were used in pairwise comparisons of controls and treatments to identify treatments that show significant differences in univariate community attributes $(p<0.05)$.

Species abundance data were presented in $k$-dominance plots, in which species are ranked in decreasing order of dominance. The percentage cumulative abundance ( $k$-dominance) is then plotted against the species rank $k$ (Lambshead et al. 1983, Platt et al. 1984).

Non-parametric multi-dimensional scaling (MDS) ordination with the Bray-Curtis similarity measure was performed on square-root transformed species abun- dance data to determine whether the nematode assemblages responded to different levels of organic enrichment by changes in the relative abundance of species. Pairwise analysis of similarities (ANOSIM; Clarke 1993) was carried out to test for significant differences in nematode community composition between treatments. The variability in community composition among replicates within a treatment was determined as the index of multivariate dispersion (IMD; Warwick \& Clarke 1993); an increase in the value of this index is considered to be a symptom of community stress. The contribution of individual species to the average Bray-Curtis dissimilarity between treatments was determined using the 'similarity percentages' program SIMPER (Clarke 1993).

All analyses were performed using the software package PRIMER, developed at the Plymouth Marine Laboratory (Clarke \& Warwick 1994).

Throughout the text, the shorthand codes given in Table 1 are used to identify microcosms.

\section{RESULTS}

\section{Visual observations}

The addition of powdered Ascophyllum nodosum had a visible impact on the microcosms. While the water in the undisturbed controls remained clear

Table 1 . Codes used in this article to identify microcosms

\begin{tabular}{|c|c|c|}
\hline Treatment & Sand code & Mud code \\
\hline Undisturbed control & S-control & M-control \\
\hline $1 / 16$ low addition given $16 x$ & S-low-16 & M-low-16 \\
\hline 1/8 low addition given $8 x$ & S-low-08 & M-low-08 \\
\hline 1/4 low addition given $4 x$ & S-low-04 & M-low-04 \\
\hline $1 / 2$ low addition given $2 x$ & S-low-02 & M-low-02 \\
\hline Total low addition given $1 \times$ & S-low-01 & M-low-01 \\
\hline $1 / 16$ medium addition given $16 x$ & S-med-16 & M-med-16 \\
\hline $1 / 8$ medium addition given $8 x$ & S-med-08 & M-med-08 \\
\hline $1 / 4$ medium addition given $4 \times$ & S-med-04 & M-med-04 \\
\hline $1 / 2$ medium addition given $2 \times$ & $S-m e d-02$ & M-med-02 \\
\hline Total medium addition given $1 \times$ & S-med-01 & M-med-01 \\
\hline 1/16 high addition given $16 x$ & S-high-16 & M-high-16 \\
\hline $1 / 8$ high addition given $8 \times$ & S-high-08 & M-high-08 \\
\hline $1 / 4$ high addition given $4 \times$ & S-high-04 & M-high-04 \\
\hline $1 / 2$ high addition given $2 x$ & S-high-02 & M-high-02 \\
\hline Total high addition given $1 \times$ & S-high-01 & M-high-01 \\
\hline
\end{tabular}




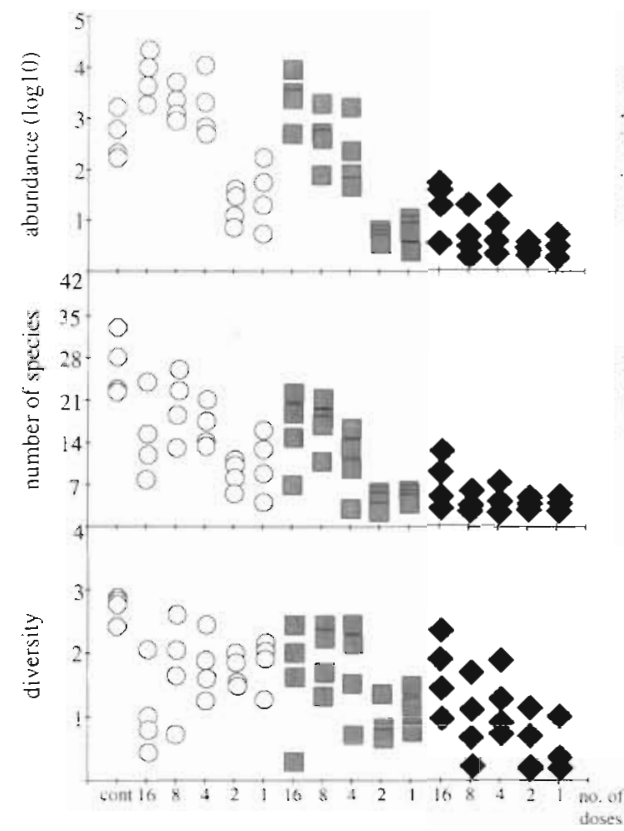

throughout the whole duration of the experiment, the water in the treatments turned opaque with increasing level of organic enrichment. Treatments developed a dark, anaerobic zone at the sediment-water interface due to hydrogen sulphide. The depth of the anoxic layer increased and the time of its appearance decreased with increasing level of organic enrichment.

\section{Univariate indices}

The graphical summary of univariate indices for nematode assemblages from the sand microcosms (Fig. 3) shows clear treatment effects according (1) to the total amount of organic matter (low, medium, high addition) and (2) to the different number of doses of organic matter (1 to 16 doses) administered during the experiment.

Results of the Kruskal-Wallis tests indicate that organic enrichment resulted in significant changes of univariate community attributes. Results from the multiple comparisons tests in Table 2 show significant differences between nematode assemblages from undisturbed controls and those from organically enriched treatments. Total nematode abundance (I) was significantly higher in the treatment S-low-16 than in the control microcosms. The number of species $(S)$ decreased significantly with an increase of the total amount of organic matter. Values were significantly lower the larger the single doses were and the less frequently they were added to the microcosms. ShannonWeaver diversity and species richness were significantly lower in most treatments than in the controls.
The response of the mud nematodes tollowed a ditferent pattern (Fig. 4, Table 2). In comparison to the controls, most univariate indices did not change significantly in the low additions. However, nematode assemblages in the medium and high additions showed a response to organic enrichment. The most common response in these treatments was a significant decrease of total nematode abundance and number of species as well as the decrease of Shannon-Weaver

Table 2. Results from the multiple comparisons tests for significant differences between nematode assemblages from the control microcosms and organically enriched treatments ( $\uparrow$ : increase in univariate measure; $\downarrow$ : decrease in univariate measure, ns: no significant difference at $p<0.05$ ). $I=$ total nematode abundance, $S=$ number of species, $H^{\prime}=$ ShannonWeaver diversity, $d=$ Margalef's species richness

\begin{tabular}{|lll|}
\hline Treatment & Sand assemblages & Mud assemblages \\
\hline Low-16 & $I \uparrow, S \downarrow, H^{\prime} \downarrow, d \downarrow$ & ns \\
Low-08 & $H^{\prime} \downarrow, d \downarrow$ & $I \downarrow$ \\
Low-04 & $S \downarrow, H^{\prime} \downarrow, d \downarrow$ & ns \\
Low-02 & $I \downarrow, S \downarrow, H^{\prime} \downarrow, d \downarrow$ & $I \downarrow$ \\
Low-01 & $I \downarrow, S \downarrow$ & $I \downarrow, S \downarrow, H^{\prime} \downarrow, d \downarrow$ \\
Med-16 & $I \uparrow, S \downarrow, H^{\prime} \downarrow, d \downarrow$ & $I \downarrow, H^{\prime} \downarrow$ \\
Med-08 & $S \downarrow$ & $I \downarrow$ \\
Med-04 & $S \downarrow, H^{\prime} \downarrow, d \downarrow$ & $I \downarrow, H^{\prime} \downarrow$ \\
Med-02 & $I \downarrow, S \downarrow, H^{\prime} \downarrow, d \downarrow$ & $I \downarrow, S \downarrow, H^{\prime} \downarrow, d \downarrow$ \\
Med-01 & $I \downarrow, S \downarrow, H^{\prime} \downarrow, d \downarrow$ & $I \downarrow, S \downarrow, H^{\prime} \downarrow, d \downarrow$ \\
High-16 & $I \downarrow, S \downarrow, H^{\prime} \downarrow, d \downarrow$ & $I \downarrow, S \downarrow, H^{\prime} \downarrow, d \downarrow$ \\
High-08 & $I \downarrow, S \downarrow, H^{\prime} \downarrow, d \downarrow$ & $I \downarrow, S \downarrow, H^{\prime} \downarrow, d \downarrow$ \\
High-04 & $I \downarrow, S \downarrow, H^{\prime} \downarrow, d \downarrow$ & $I \downarrow, S \downarrow, H^{\prime} \downarrow, d \downarrow$ \\
High-02 & $I \downarrow, S \downarrow, H^{\prime} \downarrow, d \downarrow$ & $I \downarrow, S \downarrow, H^{\prime} \downarrow, d \downarrow$ \\
High-01 & $I \downarrow, S \downarrow, H^{\prime} \downarrow, d \downarrow$ & $I \downarrow, S \downarrow, H^{\prime} \downarrow, d \downarrow$ \\
& & \\
\hline
\end{tabular}


Fig. 4. Scatter plot showing the univariate indices for nematode assemblages from each mud microcosm (diversity = ShannonWeaver index $H^{\prime}$, species richness $=$ Margalef's $d$, evenness $=$ Pielou's $J$ )

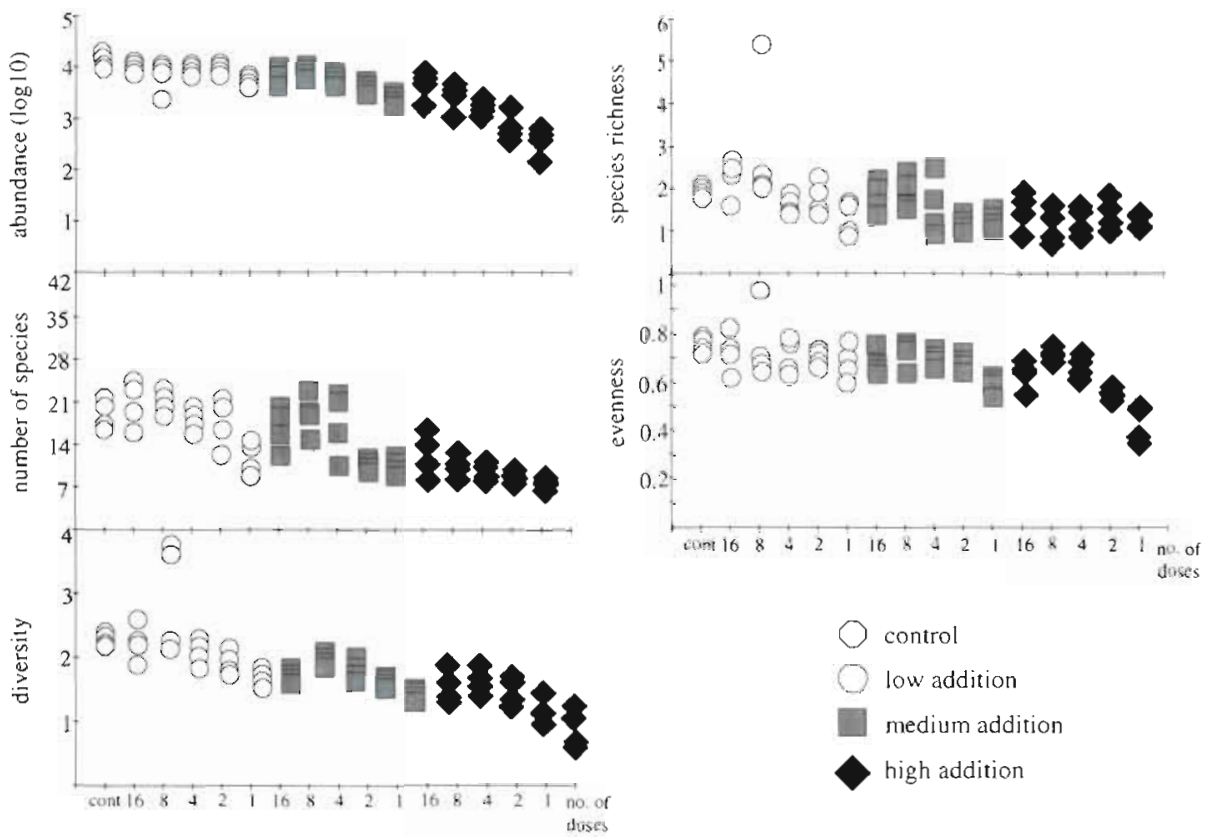

diversity and species richness in some cases as the level of organic enrichment increased.

\section{Distributional techniques}

Compared to the $k$-dominance curves of the undisturbed sand controls, the curves of disturbed sand microcosms show a clear picture of increasing dominance and decreasing diversity with increased organic enrichment (Fig. 5). In the low and medium additions, assemblages were less diverse when small doses were added frequently to the microcosms rather than a large dose given once at the beginning of the experiment. The overlapping of the $k$-dominance curves makes it difficult to discriminate between the effects of the different treatments.

As shown in Fig. 6, most organically enriched mud microcosms were less diverse and had higher dominance than the controls. As with the sand samples, a reliable statement on the effect of the size of the single doses and their frequency of addition to the microcosms on the nematode assemblages cannot be made as the $k$-dominance curves are overlapping. However, decreasing diversity and increasing dominance with increasing size/decreasing frequency of organic material was a common feature within the low, medium and high additions.

\section{Multivariate indices}

In the MDS ordinations for both the sand and the mud microcosms (Figs. $7 \& 8$ ) the effects of organic enrichment on nematode assemblages are obvious: the samples are arranged in a graded series according to the low, medium and high amounts of powdered Ascophyllum nodosum added during the experiment and the frequency of dosing.

In the plot for the sandy estuary, the disturbed microcosms are arranged around the undisturbed controls in the shape of a horseshoe. The replicates of the treatments S-low-16, S-low-08 and S-med-16 and 3 replicates of the treatment S-low-04 are placed to the lefthand side of the controls, while the other treatments extend to the right-hand side. For the low and medium additions the community composition becomes increasingly similar to the controls with increasing frequency of dosing.

In the plot for the muddy estuary, microcosms are arranged in sequence along a line with the controls situated at its left-hand end. Disturbed microcosms form overlapping clouds extending to the right. The distance between controls and treatments increases with the increasing level of dosing and decreases with the increasing frequency of dosing.

ANOSIM results reveal a significant effect of organic enrichment on nematode assemblages in both sediments. All treatments were significantly different from the controls (except for M-low-16) and a significant difference between some treatments could also be detected.

In the sand samples, variability increased (1) within treatments with decreasing number and increasing size of doses and (2) within the same number of doses as the total amount of organic matter increased. In the mud microcosms, however, the variability of the low 

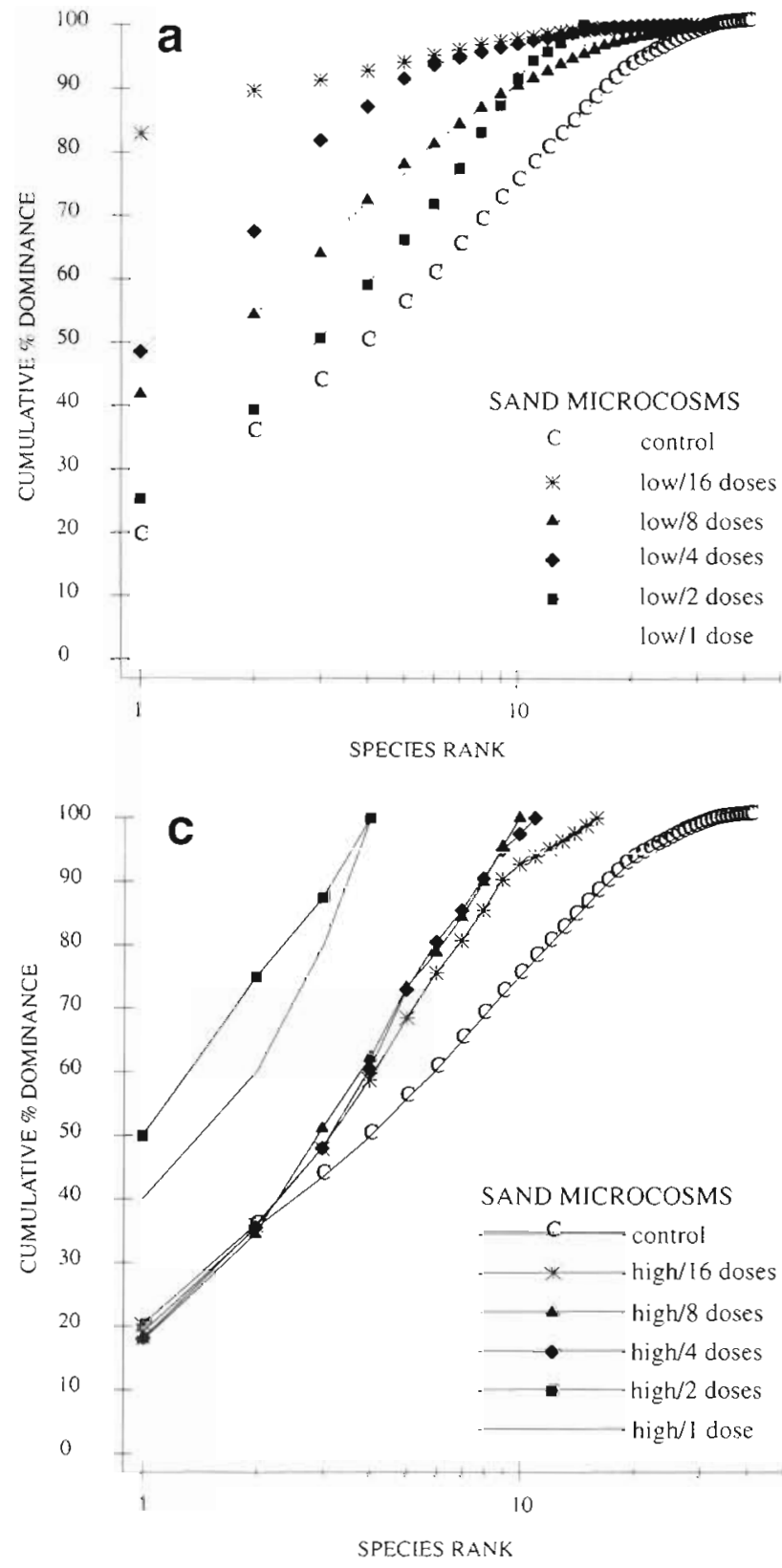

and medium additions was highest when many doses were added to the microcosms frequently.

SIMPER results show that the average dissimilarity between controls and treatments was higher in the sand microcosms ( 53 to $96 \%$ ) than in the mud microcosms ( 26 to $83 \%$ ). Two trends of increasing dissimilarity between groups are obvious in the sand microcosms: (1) within the same amount with decreasing number of doses and (2) within the same number of doses with increased total amount of organic matter.

For the muddy estuary, significant differences between microcosms did not occur when the low amount of Ascophyllum nodosum was added, regard-

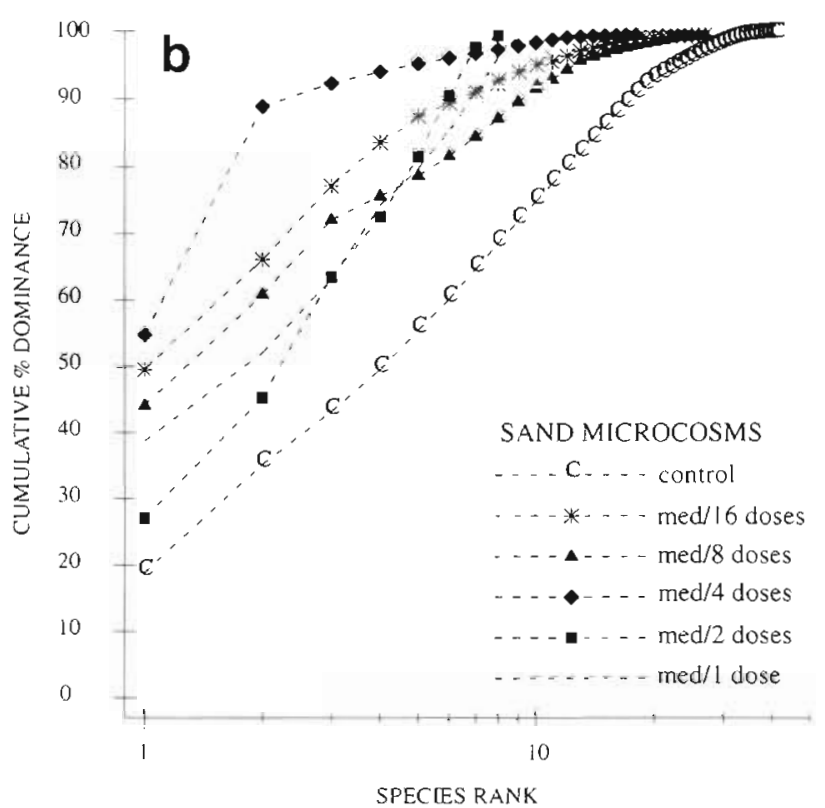

Fig. 5. k-dominance curves for sand controls and (a) low, (b) medium and (c) high additions

less of the number of doses. However, average dissimilarity between microcosms increased in the medium and high additions as the number of doses being administered declined. Within the same number of doses, increased total amount of organic matter caused an increase in the dissimilarity between samples.

Sand controls were dominated by Chromaspirina inglisi, Daptonema setosum, Odontophora longisetosa and Ascolaimus elongatus. The treatments S-low-16, S-low-08 and S-low-04 were dominated by Chromadora nudicapitata, $D$. normandicum and $C$. inglisi. Microcosms dosed with the same number of doses but with the medium amount were mainly dominated by the 2 Daptonema species $D$. normandicum and $D$. hirsutum. In low and medium additions, dosed with less than 4 doses, and in all high additions these species lost their dominance while $A$. elongatus and $O$. longisetosa became more important.

Mud controls were dominated by Terschellingia communis, T. longicaudata, Metachromadora vivipara and Sabatieria breviseta. These 4 species also accounted for about $50 \%$ of the total nematode abundance in most treatments, although $M$. vivipara and $S$. breviseta became less important in microcosms which were dosed with 2 or a single dose of powdered Ascophyllum nodosum.

Significant differences between sand microcosms mainly resulted from changes in the abundances of the dominant species (Table 3). Increasing abundances of 

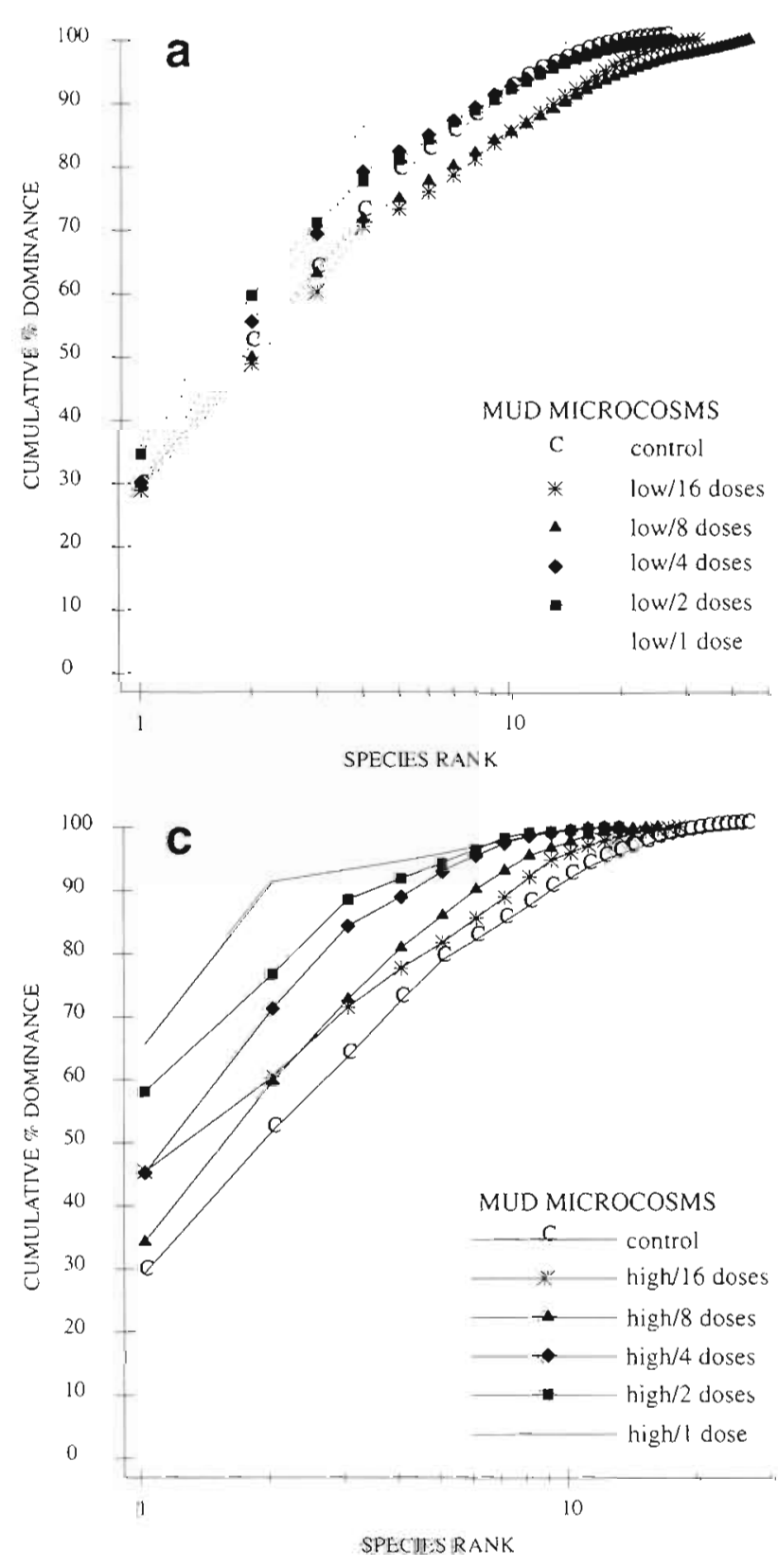

Chromadora nudicapitata and Daptonema normandicum were responsible for significant differences between undisturbed controls and the microcosms $\mathrm{S}$ low-16, S-low-08, S-low-04 and S-med-16. Abundances of $D$. hirsutum were significantly higher in the treatments S-low-08 and S-low-04 than in the control microcosms. Significant differences between controls and the samples S-med-08 and S-med-04 were mainly due to increasing numbers of $D$. hirsutum while the abundances of $D$. setosum in these samples decreased. Increasing levels of organic enrichment led to a decline in the abundances of Chromaspirina inglisi, D. setosum and Odontophora longisetosa, causing signif-

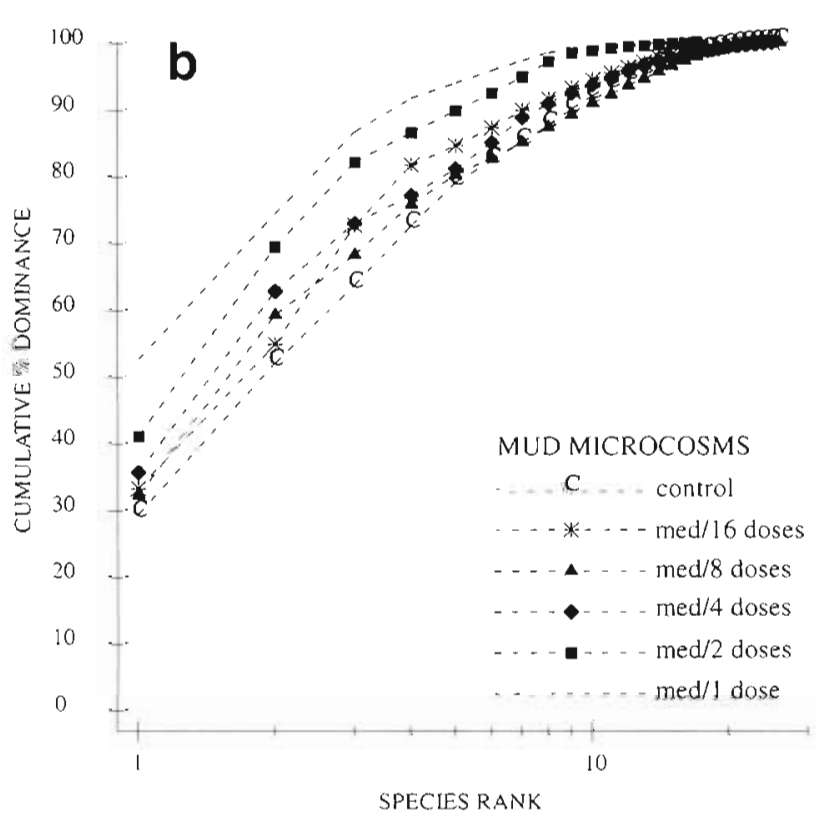

Fig. 6. k-dominance curves for mud controls and (a) low, (b) medium and (c) high additions

icant differences between controls and the microcosms S-low-02 and -01, S-med-02 and -01 and all high additions. Abundances of Thalassomonhystera parva were significantly higher in the microcosms S-med-16 than in the low treatments S-low-02 and S-low-01. Significant differences between treatment S-med-16 and the high addition treatments were based on numerical losses of C. nudicapitata and T. parva in the high addition treatments. Abundances of $D$. hirsutum and $D$. normandicum were significantly lower in the high addition treatments than in the samples S-med-08 and S-med-04.

Significant differences between undisturbed controls and organically enriched mud microcosms were mainly caused by the decrease of Ptycholaimellus ponticus and - in some cases - Dapatonema procercum. both species not being found in high numbers (Table 4). Despite their relatively low abundance, these species are good discriminators between undisturbed and organically enriched mud microcosms. Significant differences between the treatment M-low-16 and the medium addition treatments were mainly due to decreasing abundances of Chromadora nudicapitata in the medium addition treatments - another discriminating though not dominant species. Significant differences between most other disturbed microcosms were mainly based on declining numbers of the dominant species Terschellingia communis, $T$. longicaudata and Metachromadora vivipara as the level of organic enrichment increased. 


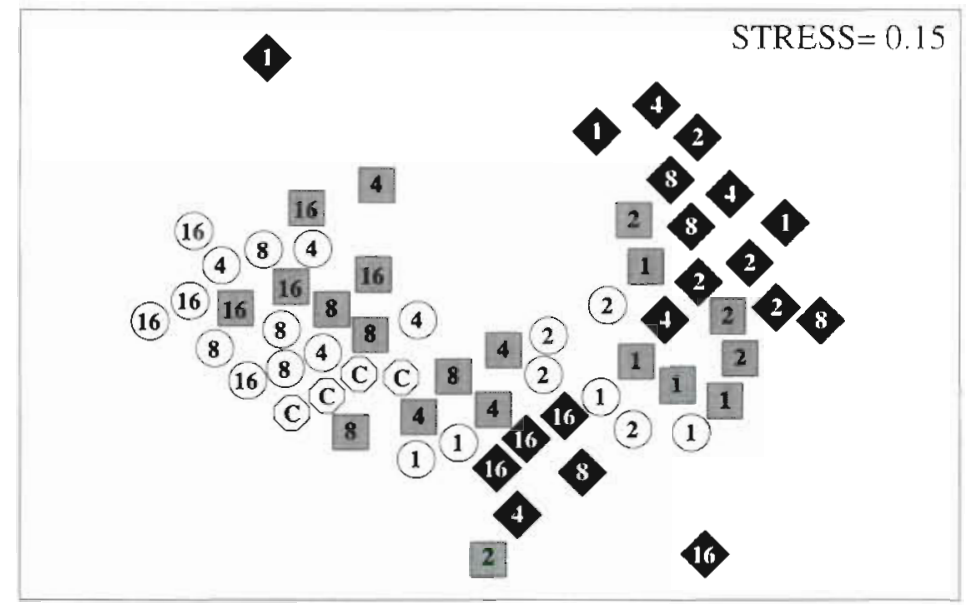

(C) control

(16) low/16 doses

(8) iow $/ 8$ doses

(4) low/4 doses

(2) low/2 doses

(1) low/l dose
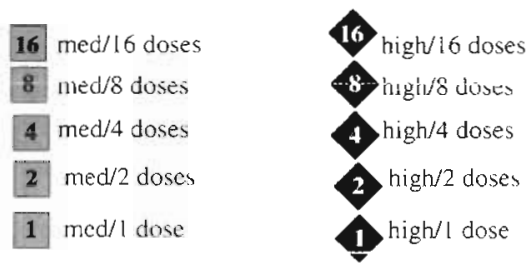

Fig. 7. MDS plot for the sand microcosms (square-root transformations)

unaffected in the $100 \mathrm{~g} \mathrm{C} \mathrm{m}^{-2}$ (low) addition. However, higher additions of organic matter resulted in significant decreases of most univariate measures.

These results reflect the negative response of most nematode species to increased levels of organic enrichment for both estuaries. It has been argued that an increased nutrient supply should result in an increase in the ecological diversity of a community (Hockin 1983). Rosenzweig (1971) and Riebesell (1974), however, showed that there is often an inverse relationship between productivity and diversity. Enrichment of competitive ecosystems sometimes leads to the extinction rather than the enhancement of species (Riebesell 1974), as occurred in this experiment.

Increased input of organic matter allowed fewer species to coexist. At high levels of organic enrichment the environmental conditions were altered to such an extent that only few species were able to survive. Susceptible species were replaced by more tolerant species.

According to Sandulli \& De Nicola Giudici

\section{DISCUSSION}

This microcosm experiment successfully tested the effects of organic enrichment on nematode communities in estuarine sand and in estuarine mud. Marked responses were revealed which led to characteristically altered community structures, depending on (1) the total quantity of organic matter being added to the microcosms, (2) the number and size of doses being administered throughout the $62 \mathrm{~d}$ duration of the experiment and (3) the composition of the communities and the environment where they developed naturally, affecting their tolerance to organic enrichment

Characteristic responses of sand and mud nematode assemblages in terms of abundance, diversity, species richness and evenness were revealed. Sand nematodes showed clear treatment effects according to (1) the total amount of organic matter (low, medium, high additions) and (2) the different number of doses of organic matter (1 to 16 doses) administered during the experiment. Total abundance, diversity and species richness decreased significantly with increasing level of organic enrichment, whereas evenness increased. Nematode assemblages from the organically rich muddy estuary remained

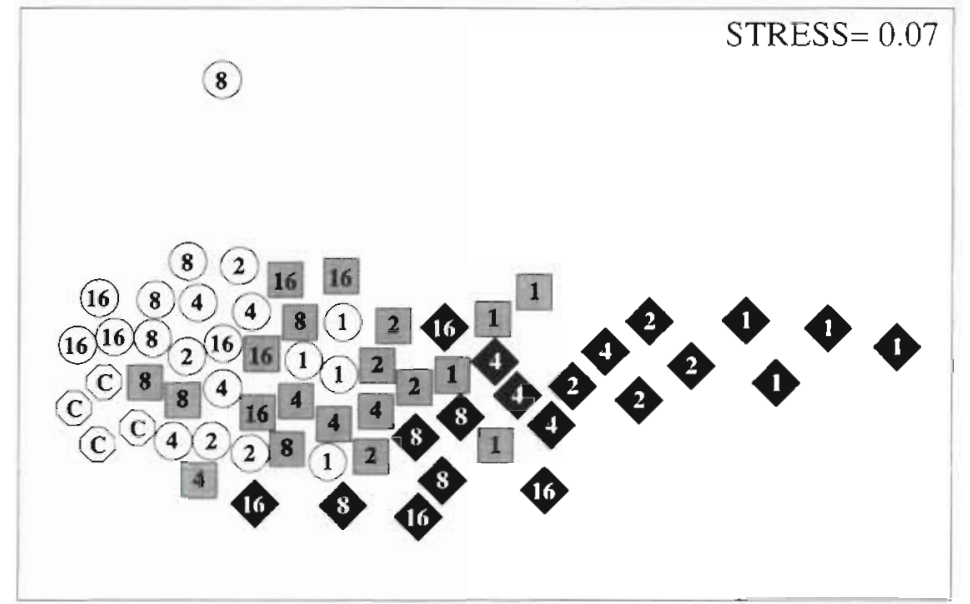

(C) control
(16) low/16 doses
(8) low/8 doses
(4) low $/ 4$ doses
(2) low/2 doses
(1) low/l dose

$16 \mathrm{med} / \mathrm{i} 6 \mathrm{doses}$

$8 \mathrm{med} / 8$ doses

$4 \mathrm{med} / 4$ doses

$2 \mathrm{med} / 2$ doses

1 med// dose

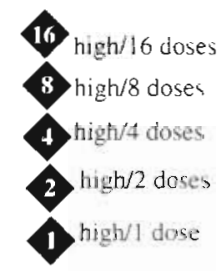

Fig. 8. MDS plot for the mud microcosms (square-root transformations) 


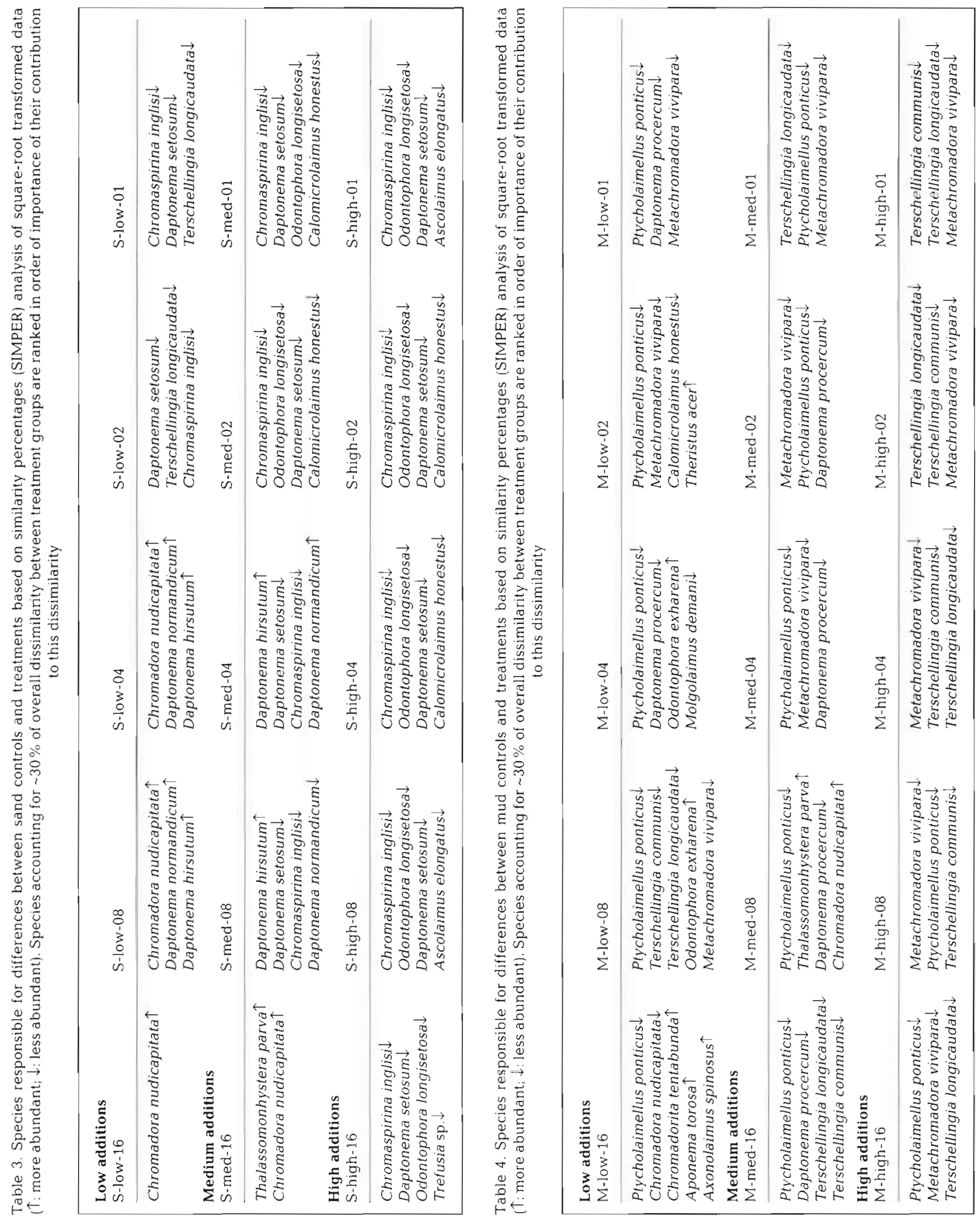


nodosum to the microcosms created highly reduced sediment conditions, as evident from the dark colour of the sediment in the treatments and the smell of hydrogen sulphicle.

Nematode communities, sampled in the organically poor sandy estuary changed more drastically in the course of the experiment than the nematode assemblages derived from the organically rich muddy estuary. Concerning the high mortality of the sand nematodes, it is reasonable to assume that those species most affected, including several to the point of total extinction, reflect the low ecological tolerance expected in communities inhabiting a less organically enriched environment at the field sampling site (Sandulli \& De Nicola Giudici 1989). Commensurate with this, $k$-dominance curves for the sand and mud microcosms showed a clear picture of decreased diversity and increased dominance in the high addition treatments.

The fact that diversity of the mud nematode communities in the low addition treatments was unaffected suggests that the assemblages in the treatments reached an organised structure similar to that of the controls. In contrast the multivariate species-dependent MDS was more sensitive in discriminating the communities, suggesting that the dominance relationships among species changed in the treatments compared to the controls (Colangelo et al. 1996).

Multivariate analysis of the data revealed significant differences between controls and treatments (except for M-control and M-low-16) for both sediment types. It seems likely that the response of natural communitjes to organic enrichment will be dependent on both the load of organic matter and the composition of the community with respect to the ratio of bacterial- and detrital-feeding species (Hockin 1983). A moderate load of organic matter will favour those species which use Ascophyllum nodosum detritus directly as a food source, while subsequent bacterial action will favour bacterial feeders. Further bacterial action however will. increase the concentration of ammonia in the sediment, which in turn may result in the extinction of species which cannot survive in oxygen-deficient sediments.

According to Wieser (1953), nematode species can be divided into 4 groups in relation to the structure of their buccal cavity. These morphological divisions represent different types of feeding mechanisms: Group $1 \mathrm{~A}=$ selective deposit feeders with no buccal cavity, feeding on bacteria-sized particles; Group $1 \mathrm{~B}=$ nonselective deposit feeders with an unarmed cup-shaped buccal cavity; Group 2A = epigrowth or diatom feeders with a buccal cavity armed with small teeth; Group 2B = predators with a large, strongly armed buccal cavity often with hooked teeth
The Iow additions S-low-16, S-low-08 and S-Iow-04 were characterised by high numbers of the epigrowth feeder Chromadora nudicapitata. The abundance of this chromadorid species was stimulated by organic enrichment, probably due to an increase of suitable or available food resources (Nilsson et al. 1991). It is possible that these levels of organic enrichment did not alter the chemical composition of the sediment radically, so that increases of abundance were probably a direct result of enhancement of both the quality and variety of food resources available for exploitation by those species with the reproductive potential to take advantage of them (Gee \& Warwick 1985). In the natural environment it is likely that the population dynamics of $C$. nudicapitata is limited by processes controlling organic matter input or residence time within the sediment (Webb 1996).

All other treatments were dominated by non-selective deposit teeders, In the treatments S-med-16, Smed-08 and S-med-04 this feeding group was mainly represented by Daptonema setosum, which was replaced by Ascolaimus elongatus and Odontophora ionyiseiusd ds lite level of uryanit eñrichment increased. It is likely that this change in community structure was caused by factors related to organic enrichment (e.g. changes in sediment chemistry) rather than being a direct result of the amount of organic matter itself.

All feeding types were represented in the nematode communities of the mud microcosms. The 2 Terschellingia species $T$. communis and $T$. longicaudata, Metachromadora vivipara and Sabatieria breviseta represented the most dominant species, all characterised by low oxygen consumption rates (Warwick \& Price 1979). This is of advantage in oxygen-poor, organically enriched sediments. Abundances of $M$. vivipara and $S$. breviseta decreased with increasing level of organic enrichment. Bacterial action increased with increasing decomposition of organic matter in the microcosms favouring species feeding on bacteria like $T$. communis and $T$. longicaudata

Microcosms from both estuaries showed a characteristic pattern in the multivariate ordinations. In the MDS plot for the sand nematodes, the samples are arranged in the shape of a horseshoe with the controls occupying an intermediate position. The horseshoe pattern reflects the extreme, exponential response of nematode communities to organic enrichment in 2 directions (Fig. 9).

The low addition treatments S-low-16, S-low-08 and S-low-04 as well as the medium addition S-med-16 are found on the left-hand side of the controls. These treatments were characterised by significantly higher numbers of Chromadora nudicapitata and the Daptonema species $D$. normandicum and $D$. hirsutum than the con- 
Fig. 9. Schematic diagram of the contributions of the most important species to the multivariate ordination for sand microcosms

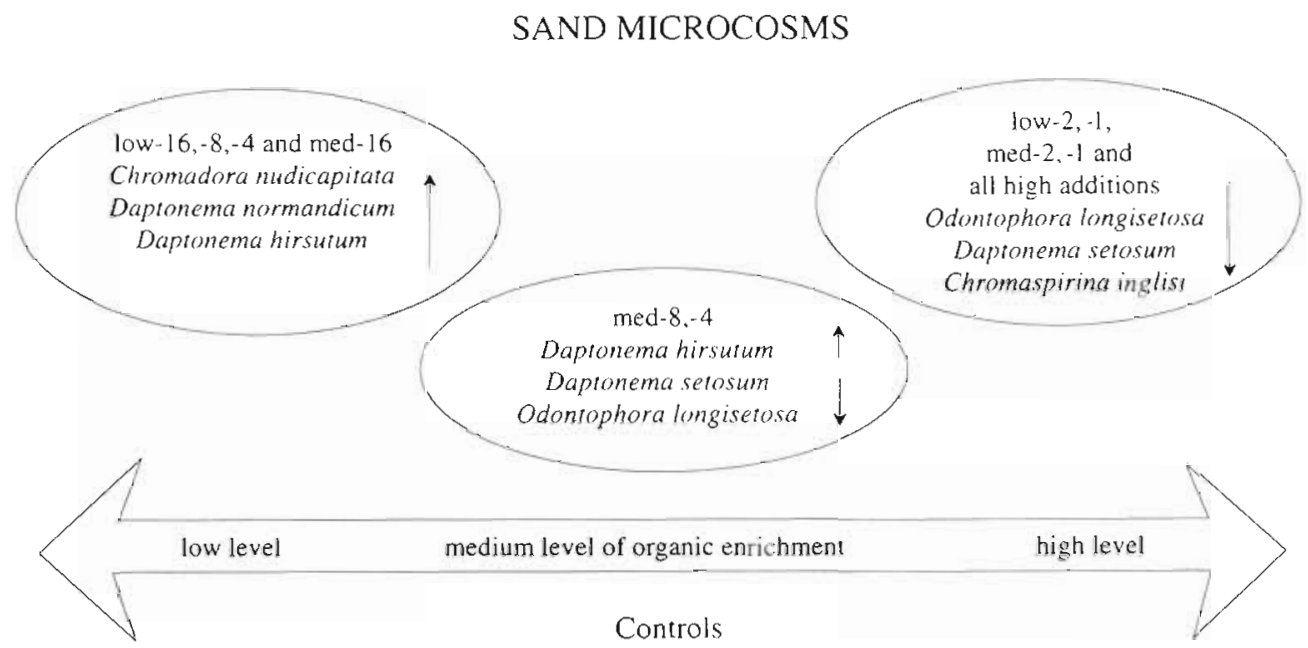

Fig. 10. Schematic diagram of the contributions of the most important species to the multivariate ordination for mud microcosms

MUD MICROCOSMS

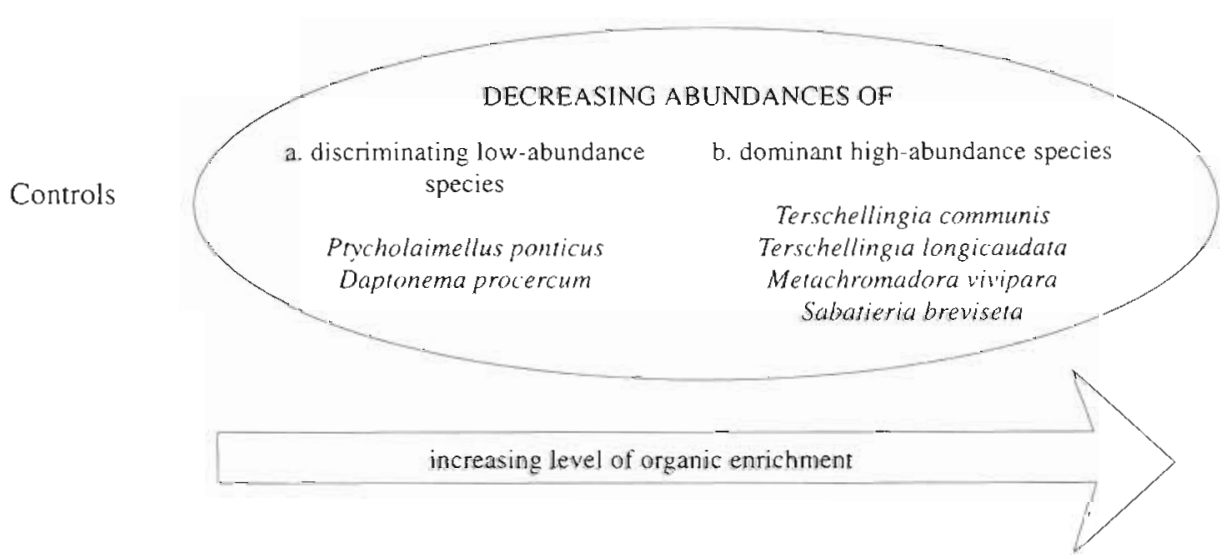

trols. The medium addition treatments S-med-08 and S-med-04 occupy an intermediate position close to the controls. These microcosms were still characterised by significantly higher numbers of $D$. hirsutum, whereas abundances of $D$. setosum and Odontophora longisetosa - both dominant species in the undisturbed microcosms - began to decrease significantly compared to the controls. The low addition treatments Slow-02 and S-low-01, the medium addition treatments S-med-02 and S-med-01 and all the high addition treatments are placed to the right-hand side of the controls, reflecting further significant decreases of $O$. longisetosa and $D$. setosum and a decrease of Chromaspirina inglisi.

In the MDS plot for the mud nematodes, the samples are arranged along a line. Changes in community structure were not as extreme as for the microcosms from the sandy estuary and the response occurred in only 1 direction (Fig. 10).

The increasing amount of organic matter and decreasing number of doses led to a decrease of diver- sity of the nematode assemblages because dominant species like Terschellingia communis, T. longicaudata, Metachromadora vivipara and Sabatieria breviseta decreased in number. Increasing levels of organic enrichment also caused extinction or stabilisation at low numbers of other, low-abundance species such as Ptycholaimellus ponticus and Daptonema procercum. The pattern of the MDS plot for the mud nematodes is mainly based on a continuous decrease of the abundances of these 6 species with increasing disturbance.

The results of this experimental study have management implications for the marine environment. It has been demonstrated that excessive organic enrichment leads to characteristically altered nematode communities. The response to changes in the organic content of the sediment and overlying water, e.g. through waste disposal and sewage sludge dumping, will depend not only on the total amount of organic matter, but also on the pattern in which this amount is released into the environment. An amount of organic matter administered in many small doses does not necessarily have a 
milder effect on community structure than the same amount administered in fewer but larger doses. More experimental research on the effects of different types, intensities and frequencies of organic enrichment on community structure will be necessary if the best practical environmental option proves to be the disposal of wastes into the marine environment.

Acknowledgements. We thank David Pearce for assistance in field sampling and in maintaining the experiment, Melanie Austen for helpful advice and Sergio Netto for assistance in maintaining the experiment. We are grateful to Bob Clarke, Martin Carr and Paul Somerfield for advice on the statistical analyses and to Hjalmar Thiel for helpful comments on an earlier draft of the manuscript. The work was supported by a European Community MAST programme training grant to M.S., Contract no. MAS3-CT96-5041. This article is based on a doctoral study by M.S. in the Faculty of Biology, University of Hamburg

\section{LITERATURE CITED}

Austen MC, McEvoy A, Warwick RM (1994) The specificity of meiobenthic community responses to different pollutants: results from microcosm experiments. Mar Pollut Bull 28: $557-563$

Austen MC, Warwick RM (1995) Effects of manipulation of food supply on estuarine meiobenthos. Hydrobiologia 311: $175-184$

Clarke KR (1993) Non-parametric multivariate analyses of changes in community structure. Aust $J$ Ecol 18:117-143

Clarke KR, Warwick RM (1994) Change in marine communities: an approach to statistical analysis and interpretation. Plymouth Marine Laboratory, Plymouth

Colangelo MA, Macri T, Ceccherelli VU (1996) A field experiment on the effect of two types of sediment disturbance on the rate of recovery of a meiobenthic community in a eutrophicated lagoon. Hydrobiologia 329:57-67

Conover WJ (1980) Practical nonparametric statistics. John Wiley \& Sons, New York, p 229-239

Coull BC, Chandler GT (1992) Pollution and meiofauna: field, laboratory and mesocosm studies. Oceanogr Mar Biol Annu Rev 30:191-271

Elliott JM (1971) Statistical analysis of samples of benthic invertebrates. Freshwat Biol Assoc Sci Publ 25:1-148

Gee JM, Warwick RM (1985) Effects of organic enrichment on meiofaunal abundance and community structure in sublittoral soft sediments. J Exp Mar Biol Ecol 91:247-262

Hockin DC (1983) The effects of organic enrichment upon a community of meiobenthic harpacticoid copepods. Mar Environ Res 10:45-58

Lambshead PJD, Platt HM, Shaw KM (1983) The detection of differences among assemblages of marine bunthic species based on an assessment of dominance and diversity. J Nat Hist 17:859-874

McIntyre AD, Warwick RM (1984) Meiofauna techniques. In:
Holme NA, McIntyre AD (eds) Methods for the study of marine benthos, IBH Handbook No 16, 2nd edn. Blackwell, Oxford, p 217-244

Nilsson P, Jonnson B, Lindstrom I, Sundbak L (1991) Response of a marine shallow-water sediment system to an increased load of inorganic nutrients. Mar Ecol Prog Ser 71:275-290

Platt HM, Shaw KM, Lambshead PJD (1984) Nematode species abundance patterns and their use in the direction of environmental perturbations. Hydrobiologia 118:59-66

Platt HM, Warwick RM (1983) Free-living marine nematodes. Part I. British enoploids. Cambridge University Press, Cambridge

Platt HM, Warwick RM (1988) Free-living marine nematodes. Part II. British chromadorids. Cambridge University Press, Cambridge

Riebesell JF (1974) Paradox of enrichment in competitive systems. Ecology 55:183-187

Rosenzweig ML (1971) Paradox of enrichment: destabilisation of exploitation ecosystems in ecological time. Science 171: 385-387

Sandulli $R$, De Nicola Giudici $M$ (1989) Effects of organic ennichment on meiofauna: a laboratory study. Mar Pollut Bull 20(5):223-227

Schratzberger M, Warwick RM (1998) Effects of physical disturbance on nematode communities in sand and mud: a microcosm experiment. Mar Biol (in press)

Somerfield PJ, Warwick RM (1996) Meiofauna in marine pollution monitoring programmes. A laboratory manual. Ministery of Agriculture, Fisheries and Food, Directorate of Fisheries Research, Lowestoft

Sundbäck K, Jönsson B, Nilsson P, Lindström I (1990) Impact of accumulating drifting macroalgae on a shallow-water sediment system: an experimental study. Mar Ecol Prog Ser 58:261-274

Warwick RM (1993) Environmental impact studies on marine communities: pragmatical considerations. Aust J Ecol 18: $63-80$

Warwick RM, Carr MR, Clarke KR, Gee JM, Green RH (1988) A mesocosm experiment on the effects of hydrocarbon and copper pollution on a sublittoral soft-sediment meiobenthic community. Mar Ecol Prog Ser 46:181-191

Warwick RM, Clarke KR (1993) Increased variability as a symptom of stress in marine communities. J Exp Mar Biol Ecol 172:215-226

Warwick RM, Platt HM., Somerfield PJ (1997) Free-living marine nematodes. Part III. British monohysterids. Field Studies Council, Shrewsbury

Warwick RM, Price R (1975) Macrofauna production in an estuarine mud-flat. J Mar Biol. Assoc UK 55:1-18

Warwick RM, Price R (1979) Ecological and metabolic studies on free-living nematodes from an estuarine mud-flat. Estuar Coast Mar Sci 9:257-271

Webb DG (1996) Response of macro- and meiobenthos from a carbon-poor sand to phytodetrital sedimentation. J Exp Mar Biol Ecol 203:259-271

Wieser W (1953) Die Beziehung zwischen Mundhoehlengestalt, Ernaehrungsweise und Vorkommen bei freilebenden marinen Nematoden. Ark Zool 4(26):439-484

Submitted: December 1, 1997; Accepted: February 6, 1998

Proofs received from author(s): March 27, 1998
Editorial responsibility: Otto Kinne (Editor)

Oldendorf/Luhe, Germany 